\title{
EVENTOS
}

\section{CONGRESSO PANAMERICANO DE ESCOLAS DE HOTELARIA E TURISMO}

\author{
Luiz Gonzaga Godoi Trigo ${ }^{1}$
}

O IV Congresso Panamericano das Escolas de Hotelaria e Turismo (Conphet) realizou-se em Montreal, Canadá, de 24 a 27 de outubro de 1994, e caractcrizou- se por uma organização profissional e cficiente.

Mais de quatrocentas pessoas provenientes das três Américas encontram-se em Montrcal. O destaque ficou para o México, que contou com uma delegação de duzentos estudantes. O Brasil participou com representantes do Senac-Ceatel de São Paulo; das Faculdades Hélio Alonso e Faculdades da Cidade, ambas do Rio de Janeiro; c da Pontícia Universidade Católica de Campinas de São Paulo.

Os temas tratados no IV Conphet foram variados, apesar da preocupação primária com temas concorrentes às sociedades pós-industriais como a nova ordem internacional, a globalização, o crescimento cconômico do setor de serviços e os megablocos cconômicos.

O primciro palestrante foi Eduardo Favos-Solá, responsável pelo setor de educação e formação da Organização Mundial de Turismo. Ele falou sobre "A Nova Era do Turismo"c considerou a formação profissional como fator-chave de êxito para a competição e sucesso cmpresarial. Para ele o paradigma empresarial da nova cra que se cstá configurando no mundo compreende:

a) Super-Segmentaf̧ão de Mercado - Na medida em que há necessidades mais complexas e diversas dos consumidores e exigências mutáveis de mercado. as cmpresas e profissionais precisam ser extremamente ágeis. É preciso detectar os novos nichos, as oportunidades c necessidades que surgem. As novas tecnologias $\mathrm{c}$ as mudanças rápidas nos hábitos de consumo pressionam no sentido de se estar permanentemente atento às

\footnotetext{
1. Doutorando em Educação na Unicamp. Professor e Coordenador do Curso de Turismo da PUCCAMP. (jerente do Campus do Senac- Ceatel (Centro de Fomação em Hoteiaria) em Aguas de Sĩo Pedro (SP).
} 
nuances e transformações sociais que se refletem na economia. na polj. tica e na cultura. Finalmente. o mercado vai exigir cada vez mais a qualidade, não apenas em produtos industrializados. mas tambe்m na prestação de serviços;

b) Flexihilidade - se há novas condições e exigências no mercado, evidentemente os profissionais, empresas e plancjadores precisam se adptar as novas conjunturas e viabilizar as mudanças de consumo de uma forma rápida e eficaz:

c) Rentabilidade - se por um lado a competição se torna mais acirrada. por outro os perigos de um mercado mais livre e desregulamentado se acentuam. A sobrevivência na nova era do turismo e dos senviços $\mathrm{cm}$ geral baseia-se na capacidade de garantir a rentabilidade. Uma possibilidade é a atuação de várias empresas $\mathrm{em}$ conjunto. Várias atisidades podem se complementar e oferecer produtos que se completem aproseitando uma mesma infraestnitura comum. Um exemplo claro desta atuação são as "JOINT VENTURES" entre várias compahias aéreals. A Delta c a Virgin, a Air Canada e a Air France, a British Airways c a US Air, a Americam e a Qantas, c a Luftansa c a United Airlines estão voando em parceria para aproveitar ao máximo a sua cara c complcxa infraestrutura.

O turismo ainda compete com outras empresas de lazer c animaçiōo, portanto é fundamental aprimorar os sistemas de comunicação e os fluxos administrativos e de prestação de serviços $\mathrm{cm}$ geral, de acordo com a especialidade de cada setor (transportes, hospedagem, receptivo, alimentos $\mathrm{e}$ bebidas etc.).

Entre 1990 e 2010 o crescimento anual do turismo deverá se situar em torno de 3,6\% ao ano assim distribuído:

\begin{tabular}{l}
\hline Ásia- Pacífico ........ 6,7\% ao ano \\
Américas ............. 4, $1 \%$ ao ano \\
Europa …........... 2,4\% ao ano
\end{tabular}

Apesar de ter o menor índice de crescimento, a Europa continuará a ser líder no mercado internacional de turismo e a ter um intenso fluxo interno nos países da União Européia e Associação Européia de Livre Comércio. A Europa do Leste c a Comunidade dos Estados Independentes deverão ter contínua estabilidade e aprimorar scus serviços para receberem cotas significativas deste fluxo.

A formação profissional ficará cada vez mais sujeita às pressõcs de mercado. Não há mais espaço para sistemas educacionais rígidos e cheios de dogmas pedagógicos. Os currículos e programas dos diversos cursos deverão responder às necessidades da demanda de mercado. A integração entre as cmpresas e entre cstas e as escolas de formação prossional são importantes neste processo. A formação deve abranger um amplo espectro de demanda profissional que atinge aos profissionais de base, de nível médio e gerencial. Mesmo em cconomias largamente globalizadas não se pode ignorar as características e problemáticas regionais.

Em suma, a situação da formação profissional baseia-se em alguns pontos básicos:

a) Quem vai cducar os profissionais? - As escolas

b) Quem vai coordenar o processo? - Os empregadores, ou seja, o mercado.

c) A educação será a curto, médio e longo prazo. A educação permanente já é uma necessidade indispensável, assim como a globalização da formação profissional em turismo.

Esta educação não deverá passar uma falsa idéia aos estudantes de que irá garantir um posto de trabalho concreto e permanente, mas sim oferecer uma carreira profissional sólida e consistente. Esta posição é relevante na medida em que aparece um desemprego estrutural nas sociedades capitalistas desenvolvidas, pois as novas tecnologias e métodos administrativos cxtinguem postos de trabalho gerando desemprego estrutural. Ao mesmo tempo são criados novos postos justamente no setor de serviços, onde se situa o turismo e estes novos postos precisam de pessoal especializado, com boa formação e informação.

A Organização Mundial do Turismo entende que deve atuar de forma subsidiária e com os seguintes objetivos:

a) definir padrões de qualidade aos níveis mundial e regional;

b) fornecer constantemente dados estatísticos para ajudar a resolver problemas nas áreas de Recursos Humanos;

c) fortabecer organizações nacionais de turismo;

d) definir programas-piloto (experimentais) de formação profissional.

Cheryl Young vice-Presidente da American Express Canada, comentou de sua enipresa face aos novos contextos internacionais. A American Express adquiriu a Travel Cook como uma das táticas para enfrentar a crescente globalização. A empresa tem procurado oferecer serviços multiculturais aos seus clientes ao redor do mundo. O treinamento dos funcionários obedece padrões gerais, mas o processo acontece em dois ni- 
veis concomitantes: mundial e regional. Esta preocupação tem como meta evitar que manifestações culturais ou sociais relevantes sejam prejudicadas por esquemas empresariais rigidos centralizados e distantes das realidades locais.

Kenneth R. Johston, diplomata canadense especializado cm comércio internacional, enfocou a importância dos serviços nas economias altuais. Como exemplo citou a OECD (The Organization For Economic Cooperation and Development), o clube dos paises mais ricos do munds. O setor de serviços contribui, em média, com $66 \%$ do PIB e com $70 \%$ da geração de empregos nos paises da OECD.

No NAFTA existem acordos especificos visando o setor de sen $i c ̧ o s$, mas ainda são limitados, devendo sofrer algumas alterações visando maior nivel de detalhes e facilidades operacionais. O futuro do GATT, envolvendo 120 paises, igualmente deverá promover a troca de serviços entre os países signatários. De qualquerm forma, os mercados deverão ficar cada vez menos protegidos e mais interdependentes.

Pierre Gvetle - do Instituto de Turismo e Hotelaria de Qucbec, c François Bédard, da Universidade de Quebec em Montreal, comentaram sobre o sistema educacional canadense, especialmente da província de Quebec, enfocando o ensino de Turismo e Hotelaria

Philippe Borel, vice-presidente do grupo hoteleiro Frontenac (c ervice-presidente da Euro Disney em Paris), comentou em sua palestra a importância de "como se formar os formadores". O professor é um profissional especial que deve reunir uma séric de predicados. O primeiro deles ć ter talento e saber ensinar as pessoas. O relacionamento com os estudantes precisa ser feito com entusiasmo. O professor pode procurar formar futuros líderes entre seus alunos. Conhecimento específico profundo da disciplina e paciência completam as exigências. A escola precisa ter um ambiente agradável, onde o processo pedagógico seja também oportunidade de diversão.

Quanto aos futuros profissionais, eles precisam saber a importância de se reconhecer o cliente, ter uma visão ampla do contexto onde vão trabalhar e valorizar a competitividade e a competência

As escolas devem ensinar o essencial mas sem se ater ao minimo Além do aprendizado teórico, é importante a ligação com as empresas onde os ensinamentos práticos serão apreendidos junto ao "trade".

Pierre Lucier - vice-ministro de Educação em Quebec, e Michel Langlois da Universidade de Quebec em Montreal, comentaram os problemas do ensino em turismo e hotelaria. Langlois explicou que sua Universidade realiza revisões periódicas (a cada cinco anos) para adequar o curri- culo ao mercado. Para ele os cinco maiores desafios a serem enfrentados pela Universidad

a) o mercado turístico;

b) o cliente-cmpregador:

c) a clientcla estudantil;

d) a capacidade de formação do futuro profissional :

e) a capacidade organizacional.

Os problemas enfrentados pelas escolas canadenses não são tão diferentes daqueles existentes em outros países da América Latina. Há dificuldades para contratação de profissionais diplomados, na medida em que hotéis c companhias aéreas formam parte de seu próprio quadro. Como conseqüência, os diplomatas dos cursos superiores às vezes são vistos como ameaça aos trabalhadores sem título acadêmico ou como um gasto desnecessário. Alguns profissionais ainda vêem a formação superior como um amontoado de tcorias sociológicas supérfluas.

Existem dificuldades de se atrair os melhores estudantes, com alta capacidade intelectual, na medida em que os cursos ainda não têm um "status" equivalente às áreas mais tradicionais como Direito, Medicina ou Engenharia. Constata-se $64 \%$ de evasão dos cursos, um número bastante elevado c que cncontra padrões semelhantes nas escolas brasileiras. Esta evasão provavelmente é conseqüência destas dificuldades estruturais e sociais.

Atender ao mercado impõe desafios bastante complexos no processo de formação. É preciso estabelecer um quadro conceitual de competência para professores e alunos, encarando-os como futuros profissionais. A procura da compctência profissional, com reflexos na qualidade, exige metodologia cuidadosamente planejada e atitudes pessoais firmes como:

a) espirito de iniciativa, autonomia, criatividade:

b) saber onde c como buscar a informação:

c) saber outras línguas e culturas;

d) cultivar relações interpessoais.

Rupert Spies, da Universidade de Cornell: Claire McNicoll, da Universidade de Montreal; e Sélim Kfourv, da Eska Consultoria, também comentaram sobre a problemática da formação profissional, enfocando temas como qualidade, novas tecnologias. trabalho abstrato e eficiência, e oducação continuada.

Maristela Segura Martinez, da Universidade Autonoma de Guadalajara (México), defendeu o intercâmbio entre professores e alunos das 
diversas instituições das Américas como um meio de se estimular uma "educação internacionalizada"e como possibilidade de trocas de experiências didático-pedagógicas e conteúdos programáticos.

Finalmente, Jean-Pierre Lemasson, da Universidade de Quebcc cm Montreal, continuou a defender a proposta de intercâmbio entre pessoas oriundas de instituições de todas as Américas e talvez até mesmo de outros continentes. Comentou que cerca de $10 \%$ dos estudantes das universidades européiais deverão ter contatos internacionais no âmbito da Unĩão Européia e que o mesmo deve acontecer com os três paises do NAFTA.

O IV Conphet deixou bastante evidenciada a preocupação das várias escolas superiores do continente em se adaptarem às novas configuraçòes internacionais, especialmente no que se referc à contínua inserção de tecnologias mais sofisticadas no Turismo e Hotelaria e ao fenòmeno da globalização.

O congresso foi espaço de lançamento do número l da revista Téoros Internacional, com artigos de excelente nível. A revista ć editada pela Universidade de Quebec em Montreal, pela Organização Mundial de Turismo e pelo Centro Internacional de Formation et de Recherche en Tourism de I'UQAN (Cifort).

Os contatos com a revista podem ser feitos no seguinte endereço:

Teoros International

Université du Quebec à Montréal

C.P. 8888 Succ. A,

Montréal, Québec, Canada. H3C3P8

Telefone (514) 987-6959 - Fax (514) 987-7827

As atividades sociais do CONPEHT foram muito bem organizadas $\mathrm{e}$ contaram com a animação do numeroso grupo mexicano liderado p๕lo Sr.Trruco, presidente do Congresso. 